\title{
Cost and clinical impact of a nonmedical DPP-4 inhibitor switch in patients with diabetes
}

\author{
Steven Kheloussi, PharmD, MBA; Alicia Johns, PhD; Vincenzo Parente, PharmD; William McLay, PharmD; \\ and Michael R Gionfriddo, PharmD, PhD
}

\section{What is already known about this subject}

- Type 2 diabetes mellitus medications substantially contribute to increased pharmacy spending but offer managed care organizations some flexibility in making coverage decisions because of relative interchangeability.

- Nonmedical formulary switches are typically instituted as a cost-saving measure by health plans and have differing effects on clinical and economic outcomes.

\section{What this study adds}

- A nonmedical formulary switch to prefer linagliptin over sitagliptin at a regional health plan led to significant overall cost savings and had a neutral effect on various measures of clinical control.

- Nonmedical formulary switching can be successful if the medications are clinically interchangeable, providers are given sufficient notice, and payers make every effort to ensure a successful change.

\section{Author affiliations}

Steven Kheloussi, PharmD, MBA; Vincenzo Parente, PharmD; and William McLay, PharmD, Wilkes University, Nesbitt School of Pharmacy, Wilkes-Barre, PA. Alicia Johns, $\mathrm{PhD}$, Geisinger Center for Health Research, Department of Population Health Sciences, Danville, PA. Michael R Gionfriddo, PharmD, PhD, Geisinger Center for Pharmacy Innovation and Outcomes, Forty Fort, PA.

\section{AUTHOR CORRESPONDENCE:}

Steven Kheloussi, 570.408.4292;

steven.kheloussi@wilkes.edu

J Manag Care Spec Pharm. 2021;27(7):846-54

Copyright $\odot 2021$, Academy of Managed Care Pharmacy. All rights reserved.

\section{ABSTRACT}

BACKGROUND: Nonmedical formulary switches (NMFS) routinely occur in managed health care plans and involve changing preferred medications for reasons outside of clinical considerations. The cost implications of NMFS are infrequently published and the clinical outcomes rarely assessed.

OBJECTIVE: To assess the real-world clinical and cost implications of an NMFS involving sitagliptin and linagliptin.

METHODS: An NMFS was made to the Geisinger Health Plan (GHP) commercial, health care reform, and Medicaid formularies on February 1, 2018, involving a change in preferred medication from sitagliptin to linagliptin. Claims data from GHP and clinical information from electronic health records of the Geisinger Health System were used to evaluate the cost and clinical impact of this change. Patients aged 18 years or older who were continuously enrolled in a GHP commercial, health care reform, or Medicaid plan throughout the entire study period and had at least 1 fill for sitagliptin during the preswitch phase were included in the study. We investigated the differences in various clinical and economic outcomes from pre- to postswitch among those who switched and remained adherent to the new preferred therapy throughout the 12-month postperiod ("linagliptin switch" group) and patients who did not ("other switch" group). Clinical outcomes included all-cause hospitalization, diabetes-related hospitalization, and glycosylated hemoglobin (HbA1c), while economic measures included changes in per member per month
(PMPM) spending. The negative binomial regression model was used to estimate utilization counts. A generalized linear model with a log link and gamma distribution was used to analyze cost data.

RESULTS: 1,203 patients met the inclusion criteria. Of these, 501 (41.6\%) individuals switched to and remained at least $80 \%$ adherent to linagliptin in the postperiod, while 702 (58.4\%) did not. No difference between groups was found when comparing the pre- to postswitch change in all-cause hospitalization (incidence rate ratio $(\mathrm{IRR})=1.46,95 \% \mathrm{Cl}=0.66-3.23, \mathrm{P}=0.3436)$ or diabetes-related hospitalization (IRR $=1.39$, $95 \% \mathrm{Cl}=0.62-3.10, P=0.4203$ ). Additionally, no difference was found between groups regarding the change in $\mathrm{HbAlc} 12$-month postswitch compared with baseline (difference between groups $=-0.10 \%$, 
$95 \% \mathrm{Cl}=-0.39 \%-0.19 \%, P=0.4962)$. Total PMPM spending was $43 \%$ higher in the other switch group compared with the linagliptin switch group $(\mathrm{IRR}=1.43,95 \% \mathrm{Cl}=1.25-1.63, \mathrm{P}<0.0001)$. This trend was driven by $92 \%$ higher medical PMPM spending in the other switch group compared with the linagliptin switch group (IRR $=1.92,95 \% \mathrm{Cl}=1.58$ $2.33, P<0.0001$ ) but was offset by $12 \%$ lower pharmacy PMPM spending in the other switch group $(\mathrm{IRR}=0.88,95 \% \mathrm{Cl}=0.82-0.95$, $P=0.0009$ )

CONCLUSIONS: An NMFS from sitagliptin to linagliptin resulted in overall health plan savings with no significant changes in health outcomes.

Type 2 diabetes mellitus (T2DM) remains one of the most prevalent chronic diseases in the United States, affecting more than 30 million individuals. ${ }^{1}$ This led to an estimated total cost of $\$ 327$ billion in 2017, of which approximately \$49 billion was spent on antidiabetic medications or supplies. $^{2}$

There are a number of medications available to manage T2DM. One available class of medications, the dipeptidyl peptidase-4 (DPP-4) inhibitors offer simple oral dosing schedules, the benefit of weight neutrality, and a limited adverse event profile. ${ }^{3,4}$ While few clinically important differences exist among available DPP-4 inhibitors, 2 agents within the class, sitagliptin (Januvia) and linagliptin (Tradjenta), are generally considered interchangeable based on their clinical profiles, and current guidelines do not recommend one agent over another. ${ }^{3-6}$

The clinical similarities between these agents allow managed care organizations flexibility in deciding which is covered on the plan's formulary. When the determination to discontinue coverage of a current formulary medication in favor of a new preferred alternative is made for reasons outside of clinical considerations, this is sometimes called a nonmedical formulary switch (NMFS). ${ }^{7}$ An NMFS commonly involves health plans changing preferred medications to those with lower list prices and/or those with available manufacturer rebates and are typically used by health plans to reduce spend. However, an NMFS may have differing effects on clinical and economic outcomes.

A recent meta-analysis found that NMFS are generally associated with negative or neutral effects on patient health (eg, emergency room visits and hospitalizations, measures of disease control, and adverse drug events); adherence; and satisfaction, as well as economic outcomes across a range of conditions. ${ }^{8}$ Existing research on the effect of NMFS for DPP-4 inhibitors is scarce and fails to examine important clinical and economic outcomes. ${ }^{9,10}$ To address this gap, we examined the effect of an NMFS from sitagliptin to linagliptin on a variety of clinical and economic outcomes.

\section{Methods}

We conducted a retrospective before and after study evaluating the effect of an NMFS at Geisinger Health Plan (GHP). Geisinger is an integrated delivery system, consisting of a network of hospitals, providers, other ancillary services, and a health plan. GHP is a regional managed care organization that offers a variety of products, including commercial, health care reform, Medicare, and Medicaid lines of business and covers over 600,000 members primarily across the northeastern and central Pennsylvania geographic region. We compared the outcomes before and after an NMFS among patients who switched and adhered to the newly preferred medication and those who did not. To address this question, we used clinical data from Geisinger's electronic medical record and claims data from GHP. A data broker employed by Geisinger extracted and deidentified data from these sources for analysis by a biostatistician.

On February 1, 2018, GHP updated the formulary for its commercial, health care reform, and Medicaid lines of business to prefer linagliptin over sitagliptin. Specifically, sitagliptin was moved from the preferred brand tier to a nonformulary position, while linagliptin was moved from a nonformulary position to the preferred brand tier. On the effective date of the switch, a prior authorization was instituted for sitagliptin, which limited coverage to members who experienced previous trial and failure on, intolerance to, or contraindication to linagliptin. Affected members, providers, and pharmacies were notified approximately 2 months in advance of the change. Communications encouraged preemptive switching to the new preferred agent. Before data collection, approval was received from the Geisinger Institutional Review Board.

Individuals were included in the analysis if they were continuously enrolled under a GHP commercial, health care reform, or Medicaid plan throughout the entire study period (June 1, 2017-May 1, 2019), were aged at least 18 years at the start of the study period, and had at least 1 fill for sitagliptin between June 1, 2017, and February 1, 2018 (Figure 1). Individuals were excluded if they passed away or switched insurance type (eg, from commercial to health care reform) during the study.

After inclusion, each individual's index date was determined in 1 of 2 ways. First, if the individual was switched to linagliptin before the formulary switch date (February 1, 2018), the index date was defined as the date of first 


\section{FIGURE 1 Study Timeline}

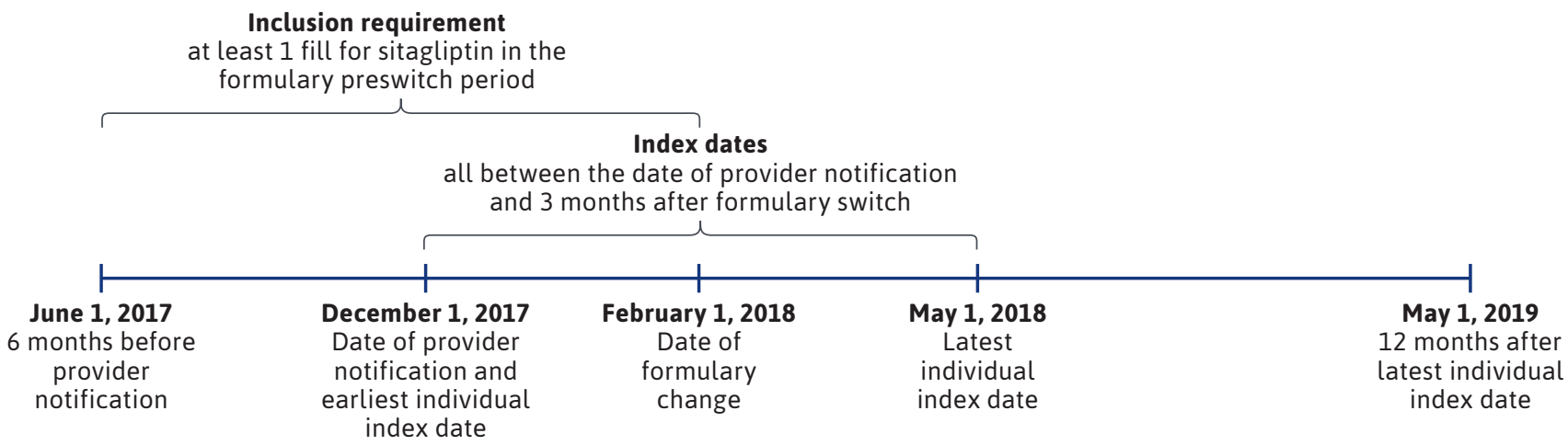

linagliptin fill after December 1, 2017, the approximate date of the member notifications. If no linagliptin claims were billed after December 1, 2017, the member's index date was defined as the date on which the member would no longer possess any sitagliptin tablets after the last fill before the formulary switch date of February 1, 2018, assuming 100\% adherence. Claims for sitagliptin after the formulary switch date imply that the member received continuous coverage for the medication following prior authorization approval. The periods before and after the index date were deemed the pre- and postswitch periods, respectively. Outcomes were assessed 12 months after each person's index date.

Individuals were categorized into 2 groups based on their post-index date medication use. Individuals who filled enough linagliptin to maintain a proportion of days covered (PDC) of $80 \%$ or more throughout the entire postswitch period were included in the "linagliptin switch" group. Those who did not maintain a PDC of $80 \%$ or more for linagliptin or who did not fill linagliptin throughout the postswitch period were included in the "other switch" group.

We evaluated the difference in the change from the preto postswitch periods between the linagliptin switch group and the other switch group on a variety of clinical and economic outcomes defined a priori, including all-cause hospitalization, diabetes-related hospitalization, glycosylated hemoglobin (HbA1c), and per-member per-month (PMPM) spending. All outcomes were extracted from claims data with the exception of HbA1c, which was extracted using data from the electronic medical record.

We analyzed PMPM spending several ways: total, medical only, and pharmacy only PMPM spending for all lines of business; combined total PMPM spending for commercial and health care reform lines of business; and total
PMPM spending for Medicaid. Commercial and health care reform spend were combined for analysis because of benefit design similarities between these lines of business and differences compared with the Medicaid line of business. Hospitalizations were classified as diabetes related based on the presence of diabetes-associated International Classification of Diseases, Tenth Revision, Clinical Modification diagnosis codes (Supplementary Table 1, available in online article). The change in HbA1c was determined using the value closest to the index date in the preswitch period and the value furthest from the index date for the postswitch period. Medication use in the preswitch period was determined based on the number of patients with at least 1 claim for the medication or medication class in question.

\section{STATISTICAL ANALYSIS}

Descriptive statistics (means, SDs, medians, and interquartile ranges for continuous variables) and frequency percentages for categorical variables are presented. Demographic variables, medication-related variables, and preperiod medication class utilization were compared between the linagliptin switch and other switch groups using a chi-square test or Fisher's exact test.

Continuous data were analyzed with a Student's t-test if the data were normally distributed or a Mann-Whitney test if the data were not normally distributed. The negative binomial regression model was used to estimate the utilization counts. A generalized linear model with a log link and gamma distribution was used for the cost data analysis.

Both models were adjusted for age at index date; Charlson Comorbidity Index scores at index date; HbA1c, body mass index (BMI), sex, insurance type, glucagon-like 


\section{FIGURE 2 Patient Selection for Study Inclusion and Analysis}

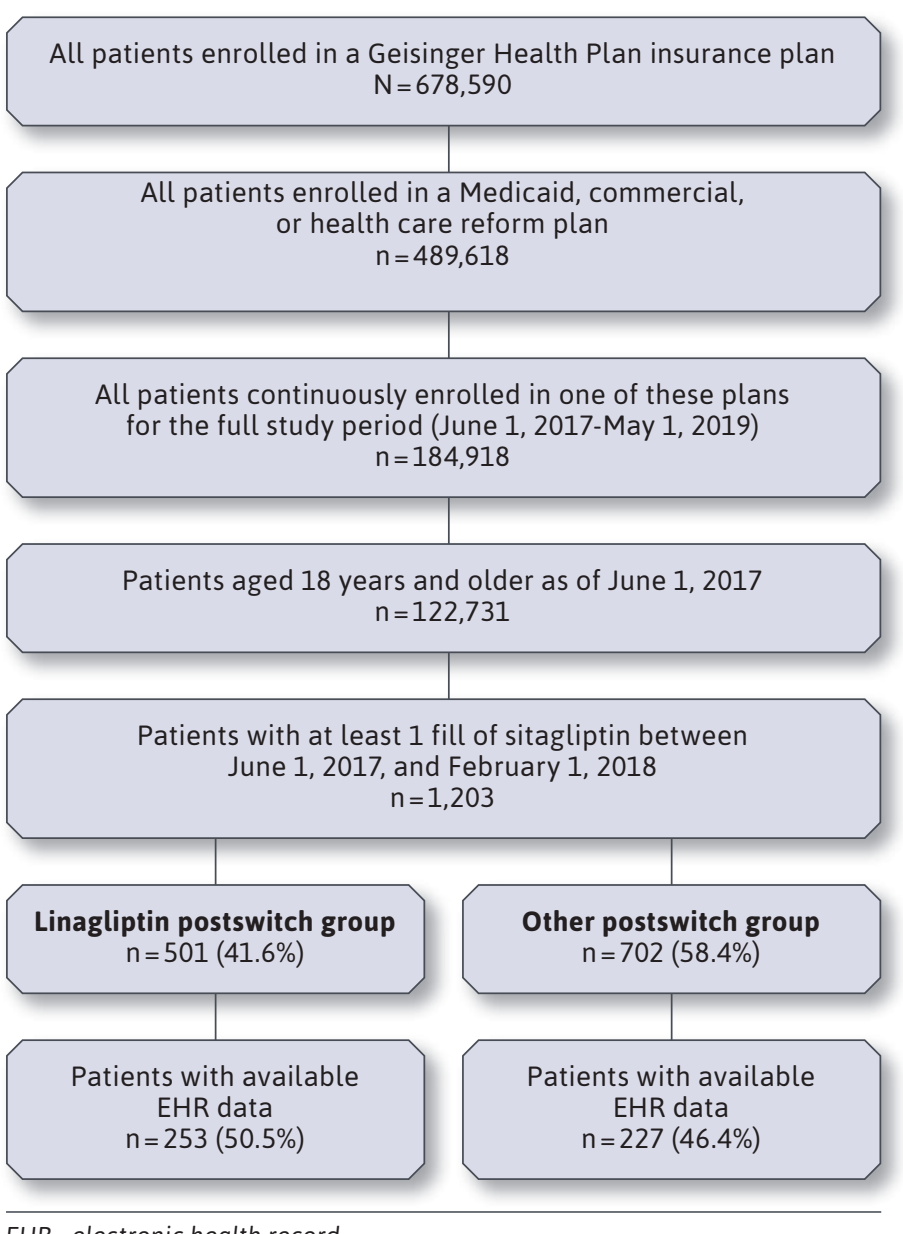

$E H R=$ electronic health record.
All analyses were conducted in SAS version 9.4 (SAS Institute). Statistical significance was defined as $\mathrm{P}<0.05$.

\section{Results}

We identified 1,203 members who met the inclusion criteria and were included in the analysis (Figure 2). Of these, 501 (41.6\%) individuals were included in the linagliptin switch group, and $702(58.4 \%)$ were categorized into the other switch group. Of the 702 patients categorized into the other switch group, 309 (44.0\%) had at least 1 fill for linagliptin but did not remain at least $80 \%$ adherent throughout the postswitch period. Overall, the population had a mean (SD) age of 53.7 (9.48) years; $46 \%$ were female; the mean (SD) BMI was $35.9(8.10) \mathrm{kg} / \mathrm{m}^{2}$; the mean (SD) HbA1c at baseline was $7.7 \%$ (1.58); and patients used an average (SD) of 2.8 (0.97) antidiabetic medications from 2.6 (1.10) medication classes. Nearly half (48.1\%) of the cohort received care within the Geisinger system, but this, and several other baseline characteristics, differed between groups (Table 1).

\section{CLINICAL OUTCOMES}

We did not observe a statistically significant difference in the rate of change in either all-cause hospitalizations (IRR $=1.46,95 \% \mathrm{CI}=0.66-3.23, \mathrm{P}=0.3436)$ or diabetes-related hospitalizations (IRR=1.39, 95\% CI=0.62-3.10, $\mathrm{P}=0.4203$ ) from pre- to post-NMFS between the linagliptin switch group and the other switch group (Table 2). Similarly, we did not detect a statistically significant difference in HbA1c change from pre- to post-NMFS between the groups (difference between groups $=-0.10 \%, 95 \% \mathrm{CI}=-0.39 \%-0.19 \%$, $P=0.4962$ ).

Changes in hospitalizations from the preswitch period to the postswitch period were also analyzed within each group. Statistically significant decreases in the rate of change were seen for patients in the linagliptin switch group for all-cause hospitalizations (difference between post- and preswitch periods $=-0.15, \quad$ IRR $=0.19,95 \% \mathrm{CI}=0.06-0.58$, $\mathrm{P}=0.0036)$ and diabetes-related hospitalizations $(-0.13$, $I R R=0.17,95 \% C I=0.05-0.52, P=0.008)$. No statistically significant differences were identified in these outcomes for the other switch group (Table 2).

In contrast to the other clinical outcomes, we observed statistically significant differences in medication use between the linagliptin switch and other switch groups. Patients in both groups had at least 1 claim for fewer unique diabetes medications in the postswitch phase compared with the preswitch period, which statistically significantly favored the linagliptin switch group (difference between ing that value by 100 . 


\section{TABLE 1 Baseline Demographics}

\begin{tabular}{|c|c|c|c|c|}
\hline & All patients & Linagliptin switch & Other switch & $P$ value \\
\hline \multicolumn{5}{|l|}{ Percentage of patients on each medication class } \\
\hline $\mathrm{N}(\%)$ & 1,203 & $501 \quad(41.6)$ & $(58.4)$ & \\
\hline Age, mean (SD) & $53.7 \quad(9.48)$ & $(9.01)$ & $(9.78)$ & 0.0079 \\
\hline \multicolumn{5}{|l|}{ Sex, n (\%) } \\
\hline Female $^{a}$ & $554 \quad(46.0)$ & $228 \quad(45.6)$ & $(46.4)$ & 0.7737 \\
\hline Male & $649 \quad(54.0)$ & $273 \quad(54.4)$ & $(53.6)$ & 0.7737 \\
\hline \multicolumn{5}{|l|}{ Insurance type } \\
\hline Commercial or HCR, n (\%) & $685 \quad(56.9)$ & $(57.3)$ & $(56.7)$ & 0.8385 \\
\hline \multicolumn{5}{|l|}{ Medication regimens } \\
\hline Number of diabetes medications, mean (SD) & $7.5 \quad(4.40)$ & $7.9 \quad(4.72)$ & $7.2 \quad(4.14)$ & 0.0145 \\
\hline Number of unique diabetes medications, mean (SD) & $2.8 \quad(0.97)$ & $2.8 \quad(0.97)$ & $(0.97)$ & 0.1161 \\
\hline Number of diabetes medication classes, mean (SD) & $2.6 \quad(1.10)$ & $2.5 \quad(0.95)$ & $(1.18)$ & $<0.0001$ \\
\hline \multicolumn{5}{|l|}{ Patients on each medication class, $\mathrm{n}(\%)$} \\
\hline Sitagliptin & $1,203(100.0)$ & $501(100.0)$ & $702(100.0)$ & \\
\hline Linagliptin & $0 \quad(0.0)$ & $(0.0)$ & $(0.0)$ & - \\
\hline Biguanide & $714 \quad(59.4)$ & $288 \quad(57.5)$ & $(60.7)$ & 0.2655 \\
\hline Other DPP-4 inhibitors & $0 \quad(0.0)$ & $(0.0)$ & $(0.0)$ & - \\
\hline GLP-1 receptor agonist & $79 \quad(6.6)$ & $(3.4)$ & $(8.8)$ & 0.0002 \\
\hline Insulin & $250 \quad(20.8)$ & $90 \quad(18.0)$ & $(22.8)$ & 0.0419 \\
\hline Meglitinide & $31 \quad(2.6)$ & $(2.6)$ & $(2.6)$ & 0.9736 \\
\hline SGLT2 inhibitor & $245 \quad(20.4)$ & $103 \quad(20.6)$ & $(20.2)$ & 0.8883 \\
\hline Sulfonylurea & $491 \quad(40.8)$ & $203 \quad(40.5)$ & $(41.0)$ & 0.8601 \\
\hline Thiazolidinedione & $45 \quad(3.7)$ & $(4.0)$ & $(3.6)$ & 0.6979 \\
\hline Other antidiabetic medications & $(0.4)$ & $(0.6)$ & $(0.3)$ & 0.6547 \\
\hline \multicolumn{5}{|l|}{ Health indicators } \\
\hline Body mass index, mean (SD) & $35.9 \quad(8.10)$ & $(7.94)$ & $(8.15)$ & 0.0081 \\
\hline $\mathrm{HbA1C}$, mean (SD) & $7.7 \quad(1.58)$ & $7.5 \quad(1.47)$ & $(1.64)$ & 0.0127 \\
\hline Charlson Comorbidity Index score, mean (SD) & $2.3 \quad(1.65)$ & $2.4 \quad(1.67)$ & $(1.64)$ & 0.0717 \\
\hline \multicolumn{5}{|l|}{ Hospitalizations } \\
\hline All-cause, mean PMPM (SD) & $0.24(0.074)$ & $0.28(0.135)$ & $0.21(0.083)$ & 0.6090 \\
\hline Diabetes related, mean PMPM (SD) & $0.16(0.051)$ & $0.19(0.092)$ & $0.14(0.059)$ & 0.6588 \\
\hline \multicolumn{5}{|l|}{ Health care indicators } \\
\hline Use of Geisinger facilities, n (\%) & $(48.1)$ & $253 \quad(50.5)$ & $(46.4)$ & 0.2941 \\
\hline
\end{tabular}

ane person had an unknown sex and one had a missing value for sex.

DPP-4 = dipeptidyl peptidase 4; GLP=glucagon-like peptide; HbAlc=glycosylated hemoglobin Alc; HCR = health care reform; $P M P M=$ per member per month; SGLT2 = sodium-glucose cotransporter-2.

groups $=0.10,95 \% \mathrm{CI}=0.001-0.210, \mathrm{P}=0.048)$. Conversely, while patients in the linagliptin switch and other switch groups used fewer unique antidiabetic medication classes in the postswitch phase compared with baseline, those in the other switch group used significantly fewer unique medication classes compared with the linagliptin switch group (difference between groups $=-0.53,95 \% \mathrm{CI}=-0.69$, $-0.37, \mathrm{P}<0.0001)$. 


\section{TABLE 2 Change in Clinical Outcomes from Baseline}

\begin{tabular}{|c|c|c|c|c|c|c|c|c|c|}
\hline & $\begin{array}{c}\text { Linagliptin } \\
\text { switch group } \\
\text { difference in } \\
\text { post- and pre- } \\
\text { switch values }^{\text {a }}\end{array}$ & $\begin{array}{l}\text { IRR between } \\
\text { groups }^{\mathbf{b}}\end{array}$ & P value & $\begin{array}{l}\text { Other switch } \\
\text { group } \\
\text { difference in } \\
\text { post- and pre- } \\
\text { switch values }\end{array}$ & $\begin{array}{c}\text { IRR between } \\
\text { groups }^{\text {b }}\end{array}$ & $P$ value & \begin{tabular}{|} 
Difference \\
in difference \\
estimates \\
between \\
groups \\
\end{tabular} & $\begin{array}{l}\text { IRR between } \\
\text { groups }^{\text {d }}\end{array}$ & $P$ value \\
\hline $\begin{array}{l}\text { Change in all-cause } \\
\text { hospitalization, mean } \\
\text { PMPM }(95 \% \mathrm{Cl})^{\mathrm{e}}\end{array}$ & $\begin{array}{c}-0.15 \\
(-0.31,-0.06)\end{array}$ & $\begin{array}{c}0.19 \\
(0.06,0.58)\end{array}$ & 0.0036 & $\begin{array}{c}0.01 \\
(0.01,0.01)\end{array}$ & $\begin{array}{c}1.09 \\
(0.41,2.91)\end{array}$ & 0.8625 & $\begin{array}{c}0.16 \\
(0.07,0.32)\end{array}$ & $\begin{array}{c}1.46 \\
(0.66,3.23)\end{array}$ & 0.3436 \\
\hline $\begin{array}{l}\text { Change in diabetes- } \\
\text { related hospitalization, } \\
\text { mean PMPM }(95 \% \mathrm{CI})^{\mathrm{e}}\end{array}$ & $\begin{array}{c}-0.13 \\
(-0.28,-0.06)\end{array}$ & $\begin{array}{c}0.17 \\
(0.05,0.52)\end{array}$ & 0.0020 & $\begin{array}{c}0.008 \\
(0.005,0.007)\end{array}$ & $\begin{array}{c}1.10 \\
(0.41,2.96)\end{array}$ & 0.8550 & $\begin{array}{c}0.138 \\
(0.067,0.285)\end{array}$ & $\begin{array}{c}1.39 \\
(0.62,3.10)\end{array}$ & 0.4203 \\
\hline $\begin{array}{l}\text { Change in HbAlc (\%), } \\
\text { mean (SD) }\end{array}$ & $-0.10(1.252)$ & - & 0.2976 & $\begin{array}{l}-0.20 \\
(1.641)\end{array}$ & - & 0.0807 & $\begin{array}{c}-0.10 \\
(-0.39,0.19) \\
\end{array}$ & - & 0.4962 \\
\hline $\begin{array}{l}\text { Change in number of } \\
\text { unique diabetes medica- } \\
\text { tions, post-index date } \\
\text { with at least } 1 \text { claim, } \\
\text { mean (SD) }\end{array}$ & $\begin{array}{l}-0.4 \\
(0.71)\end{array}$ & - & $<0.0001$ & $\begin{array}{l}-0.3 \\
(1.13)\end{array}$ & - & $<0.0001$ & $\begin{array}{c}0.10 \\
(0.001,0.21)\end{array}$ & - & 0.0481 \\
\hline $\begin{array}{l}\text { Change in number of } \\
\text { unique diabetes medica- } \\
\text { tion classes, post-index } \\
\text { date with at least } 1 \\
\text { claim, mean (SD) }\end{array}$ & $\begin{array}{l}-0.4 \\
(0.80)\end{array}$ & - & $<0.0001$ & $\begin{array}{l}-0.9 \\
(1.95)\end{array}$ & - & $<0.0001$ & $\begin{array}{c}-0.53 \\
(-0.69,-0.37)\end{array}$ & - & $<0.0001$ \\
\hline
\end{tabular}

${ }^{a}$ Results represent postswitch minus preswitch least squares means estimates.

${ }^{b}$ Results represent postswitch rate ratio divided by preswitch rate ratio.

${ }^{c}$ Results represent other switch group minus linagliptin switch group least squares means estimates.

${ }^{d}$ Results represent other switch group rate ratio divided by the linagliptin switch group rate ratio.

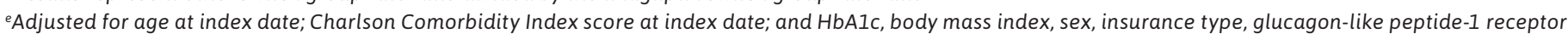
agonist use in the preperiod, and insulin use in the preperiod.

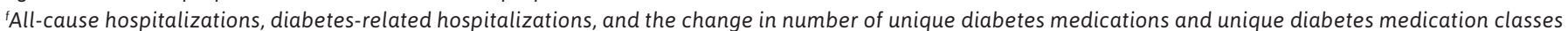

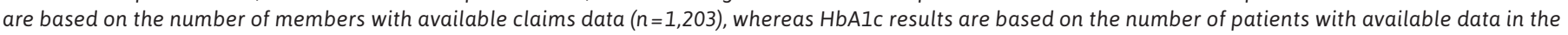
electronic medical record $(n=480)$.

$\mathrm{HbAIC}=$ glycosylated hemoglobin; $I R R=$ incidence rate ratio; $P M P M=$ per member per month .

Full details on clinical outcomes can be found in Table 2 and Supplementary Table 2 (available in online article). Additionally, the percentages of patients with at least 1 claim for each antidiabetic medication class in the post-index period are included in Supplementary Table 3 (available in online article).

\section{ECONOMIC OUTCOMES}

Total PMPM spending increased at a significantly greater rate in the other switch group compared with the linagliptin switch group $(\mathrm{IRR}=1.43,95 \% \mathrm{CI}=1.25-1.63, \mathrm{P}<0.0001)$. When PMPM spending was separated into medical and pharmacy costs, we observed a similar pattern for medical spending (IRR=1.92, 95\% CI=1.58-2.33, $\mathrm{P}<0.0001)$; however, the IRR comparing the other switch group to the linagliptin switch group was found to be 0.88 , indicating a $12 \%$ decrease in the rate of change in pharmacy PMPM spending from the pre- to postswitch periods between these 2 groups, respectively (95\% CI=0.82-0.95, P=0.0009; Table 3).

The rate of change in total PMPM spending was also analyzed by line of business. A significant increase in the rate of change was found between the other switch and linagliptin switch groups in the commercial and health care reform lines of business $(\mathrm{IRR}=1.45,95 \% \mathrm{CI}=1.18-1.79, \mathrm{P}=0.0005)$, but not for members enrolled in a Medicaid plan (IRR $=1.08,95 \%$ $\mathrm{CI}=0.93-1.26, \mathrm{P}=0.3312$ ).

We also examined the change in spending from the preswitch period to the postswitch period within each group. Preswitch total PMPM spending was $42 \%$ higher than postswitch spending in the linagliptin switch group ( $\mathrm{IRR}=1.42,95 \% \mathrm{CI}=1.17-1.71, \mathrm{P}=0.0003)$, whereas preswitch total PMPM spending was found to be $17 \%$ lower than postswitch spending for the other switch group (IRR $=0.83$, 95\% CI $=0.69-1.00, P=0.0469$ ). A similar trend was found for 


\section{TABLE 3 Change in Economic Outcomes from Baseline}

\begin{tabular}{|c|c|c|c|c|c|c|c|c|c|}
\hline & $\begin{array}{l}\text { Linagliptin } \\
\text { switch group } \\
\text { difference in } \\
\text { post- and } \\
\text { preswitch } \\
\text { values }(\$)^{\mathrm{a}}\end{array}$ & $\begin{array}{l}\text { IRR between } \\
\text { groups }^{\text {b }}\end{array}$ & $P$ value & $\begin{array}{l}\text { Other switch } \\
\text { group } \\
\text { difference in } \\
\text { post- and } \\
\text { preswitch } \\
\text { values }(\$)^{\mathrm{a}}\end{array}$ & $\begin{array}{l}\text { IRR between } \\
\text { groups }^{\text {b }}\end{array}$ & $P$ value & $\begin{array}{c}\text { Difference } \\
\text { in difference } \\
\text { estimates } \\
\text { between } \\
\text { groups }(\$)^{c}\end{array}$ & $\begin{array}{l}\text { IRR between } \\
\text { groups }^{\text {d }}\end{array}$ & $P$ value \\
\hline $\begin{array}{l}\text { Change in total } \\
\text { spending, mean PMPM } \\
(95 \% \mathrm{CI})^{\mathrm{e}}\end{array}$ & $\begin{array}{l}-826.13 \\
(-992.37 \\
-687.75)\end{array}$ & $\begin{array}{c}1.42 \\
(1.17,1.71)\end{array}$ & 0.0003 & $\begin{array}{l}622.50 \\
(490.61 \\
785.24)\end{array}$ & $\begin{array}{c}0.83 \\
(0.69,1.00)\end{array}$ & 0.0469 & $\begin{array}{l}1,448.63 \\
(1,329.60 \\
1,472.99)\end{array}$ & $\begin{array}{c}1.43 \\
(1.25,1.63)\end{array}$ & $<0.0001$ \\
\hline \multicolumn{10}{|l|}{ Spending by benefit type } \\
\hline $\begin{array}{l}\text { Change in medical } \\
\text { spending, mean PMPM } \\
(95 \% \mathrm{CI})^{\mathrm{e}}\end{array}$ & $\begin{array}{c}-849.06 \\
(-640.53 \\
-1,125.38)\end{array}$ & $\begin{array}{c}2.04 \\
(1.55,2.69)\end{array}$ & $<0.0001$ & $\begin{array}{r}474.79 \\
(343.92 \\
650.78)\end{array}$ & $\begin{array}{c}0.81 \\
(0.62,1.06)\end{array}$ & 0.1276 & $\begin{array}{l}1,323.85 \\
(984.45 \\
1,776.16)\end{array}$ & $\begin{array}{c}1.92 \\
(1.58,2.33)\end{array}$ & $<0.0001$ \\
\hline $\begin{array}{l}\text { Change in pharmacy } \\
\text { spending, mean PMPM } \\
(95 \% \mathrm{CI})^{\mathrm{e}}\end{array}$ & $\begin{array}{l}135.79 \\
(121.70 \\
151.50)\end{array}$ & $\begin{array}{c}0.87 \\
(0.79,0.97)\end{array}$ & 0.0136 & $\begin{array}{l}-197.16 \\
(-214.83 \\
-180.94)\end{array}$ & $\begin{array}{c}1.25 \\
(1.13,1.38)\end{array}$ & $<0.0001$ & $\begin{array}{l}-332.95 \\
(-336.53 \\
-332.44)\end{array}$ & $\begin{array}{c}0.88 \\
(0.82,0.95)\end{array}$ & 0.0009 \\
\hline \multicolumn{10}{|c|}{ Spending by line of business } \\
\hline $\begin{array}{l}\text { Change in total } \\
\text { spending: Medicaid, } \\
\text { mean PMPM }(95 \% \mathrm{Cl})^{\mathrm{f}}\end{array}$ & $\begin{array}{l}12.66 \\
(7.98 \\
18.95)\end{array}$ & $\begin{array}{c}0.99 \\
(0.80,1.22)\end{array}$ & 0.9333 & $\begin{array}{l}-291.16 \\
(-338.34 \\
-250.48) \\
\end{array}$ & $\begin{array}{c}1.21 \\
(0.99,1.48)\end{array}$ & 0.0580 & $\begin{array}{l}-303.82 \\
(-346.32 \\
-269.43) \\
\end{array}$ & $\begin{array}{c}1.08 \\
(0.93,1.26)\end{array}$ & 0.3312 \\
\hline $\begin{array}{l}\text { Change in total } \\
\text { spending: commercial } \\
\text { and HCR, mean PMPM } \\
(95 \% \mathrm{Cl})^{\mathrm{f}}\end{array}$ & $\begin{array}{l}-3,609.99 \\
(-5,029.58 \\
-2,590.38)\end{array}$ & $\begin{array}{c}0.46 \\
(0.34,0.60)\end{array}$ & $<0.0001$ & $\begin{array}{l}2,111.21 \\
(1,444.63 \\
3,051.92)\end{array}$ & $\begin{array}{c}1.38 \\
(1.04,1.84)\end{array}$ & 0.0269 & $\begin{array}{l}5,721.20 \\
(5,642.30 \\
6,474.21)\end{array}$ & $\begin{array}{c}1.45 \\
(1.18,1.79)\end{array}$ & 0.0005 \\
\hline
\end{tabular}

${ }^{a}$ Results represent postswitch minus preswitch least squares means estimates.

${ }^{b}$ Results represent postswitch rate ratio divided by the preswitch rate ratio.

${ }^{c}$ Results represent other switch group minus linagliptin switch group least squares means estimates.

${ }^{d}$ Results represent other switch group rate ratio divided by the linagliptin switch group rate ratio.

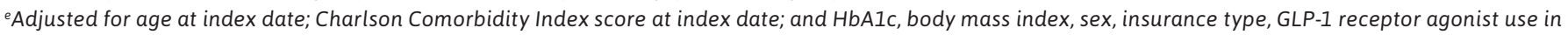
the preperiod, and insulin use in the preperiod.

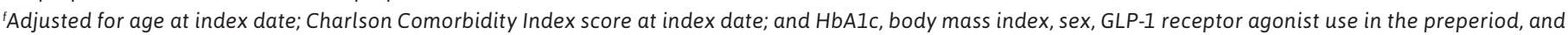
insulin use in the preperiod.

GLP-1 = glucagon-like peptide-1; HbAIC=glycosylated hemoglobin; HCR=health care reform; IRR=incidence rate ratio; $P M P M=$ eer member per month.

total PMPM commercial and health care reform spending, although no significant differences were found for total PMPM Medicaid spending (Table 3).

PMPM medical spending was higher in the preswitch period compared with the postswitch period in the linagliptin switch group $(\mathrm{IRR}=2.04,95 \% \mathrm{CI}=1.55-2.69$, $\mathrm{P}<0.0001)$ but did not change significantly for patients in the other switch group (IRR=0.81, 95\% CI=0.62-1.06, $\mathrm{P}=0.1276$ ). Conversely, pharmacy spending, on a PMPM basis, increased significantly from the pre- to postswitch periods in the linagliptin switch group (IRR=0.87, 95\% $\mathrm{CI}=0.79-0.97, \mathrm{P}=0.0136)$ and decreased significantly in the other switch group $(\mathrm{IRR}=1.25,95 \% \mathrm{CI}=1.13-1.38, \mathrm{P}<0.0001)$. Full details on economic outcomes can be found in Table 3 and Supplementary Table 4 (available in online article).

\section{Discussion}

We found that an NMFS from sitagliptin to linagliptin was associated with a lower total PMPM spending among those who switched to the newly preferred medication and remained adherent throughout the study treatment period compared with those who did not, with no significant changes in hospitalizations or HbA1c.

The decrease in total PMPM costs associated with adhering to the switch was driven by a decrease in medical spending in the linagliptin switch group, which may be related to the reduction in hospitalizations observed in this population. While the difference in rate of change in hospitalizations between groups was not statistically significant, there was a reduction among those who adhered to the switch and no significant change in those who did not. 
We observed an increase in pharmacy PMPM spending in the linagliptin switch group that may have been offset by confidential manufacturer rebates. The existence of these rebates in this situation cannot be confirmed; however, if present, rebates would further increase the cost savings associated with the NMFS. We also observed a decrease in pharmacy PMPM spending in the other switch group, which may be a result of lower medication use or use of lower cost generic medications. Additionally, adherence to medications other than linagliptin in the postperiod was not analyzed and could have affected pharmacy PMPM spending. This presents an opportunity for future study.

Existing literature on NMFS has led to mixed results. ${ }^{8}$ Most NMFS are associated with neutral clinical and economic outcomes. Our data on clinical outcomes align with this finding; however, our results also support the use of NMFS to lower overall spending. In our study, we found that patients in the linagliptin switch group experienced greater cost savings with no significant difference in clinical outcomes compared with those in the other switch group.

When instituting a switch, payers should aim to ensure as high of a conversion rate from the previous formulary medication to the newly preferred agent. No current literature exists that reports the "conversion rate" of a NMFS, defined here as the percentage of affected patients who switch and remain adherent to the newly preferred medication following an NMFS. We found that this NMFS achieved approximately a $42 \%$ conversion rate. Clinical and economic outcomes may have further improved with a greater conversion rate, although an extrapolation of our findings cannot be guaranteed. Still, payers should make every effort to ensure that patients are smoothly transitioned from the historically preferred medication to the newly preferred agent to facilitate optimal cost savings.

Before instituting an NMFS, payers must consider the clinical interchangeability of the proposed newly preferred medication with the current formulary agent. One possible reason for the success of the sitagliptin-linagliptin formulary switch that was undertaken is the clinical similarity between these agents in terms of efficacy and safety. ${ }^{5,6}$ Payers must also anticipate the potential clinical effect on all patients, including those stable on their current regimens, and properly communicate the switch prescribers. Providers frequently cite concerns with NMFS and purport that communication regarding these changes is suboptimal.,11,12 Communication for this switch was shared with prescribers 2 months in advance through various channels (mail, fax, and personal outreach to high-volume sitagliptin prescribers) to ensure buy-in.

\section{LIMITATIONS}

This study has several limitations. First, the sample size was small relative to other similar studies. ${ }^{9,10}$ This is because of the regional geographic reach of the health plan and our decision to only include patients receiving care within the Geisinger System for the clinical outcomes due to the availability of electronic health record data. Despite the relatively small sample size, however, we were able to detect differences in the clinical and economic outcomes reported. Future studies with larger samples and longer follow-up are needed to clarify the effect of this type of NMFS on other clinical outcomes (eg, medicationrelated adverse events, albuminuria, cardiovascular events, and mortality).
Second, the groups within our cohort were imbalanced at baseline for several important variables. Although we attempted to adjust for this in the analysis through our difference-in-difference design and the use of multivariate regression, there may have been important confounders that were unobserved or unadjusted for, which could have affected our results. Also, because of the short duration of the preswitch period, there was a risk of misclassification bias in the postswitch period regarding new medication starts. We tried to minimize this bias by defining the preswitch period as 4 months, which extended beyond the maximum 3-month supply of medication that can be filled at any one time.

Finally, patients were divided into 1 of 2 groups based on whether they switched and remained adherent to the postswitch preferred medication. Although this was an effective determination of real-world effect, the individual effects on other switch patients were unclear. Patients in the other switch group were heterogeneous, and different subgroups may achieve different outcomes than those observed for the overall group. For instance, if in our study, many other switch patients discontinued sitagliptin and switched to no new antidiabetic therapy, the results favoring the linagliptin switch group may have been exaggerated.

\section{Conclusions}

An NMFS from sitagliptin to linagliptin resulted in overall net savings with no significant change in health outcomes. Patients who switched and adhered to the newly preferred medication experienced improved clinical outcomes from the preswitch period to the postswitch period. 


\section{DISCLOSURES}

Funding for this study was provided by Geisinger Health System, which had no role in the study outside of a final review of the submitted manuscript. Johns and Gionfriddo are Geisinger employees. The authors report no financial conflicts of interest.

\section{ACKNOWLEDGMENTS}

The authors thank Kimberly Jones, PharmD, for her contributions to the literature review for this project, and Jason P. Brown for his contributions to data collection.

\section{REFERENCES}

1. Centers for Disease Control and Prevention. Type 2 diabetes. May 30, 2019. Accessed October 5, 2020. https://www. cdc.gov/diabetes/basics/type2.html

2. American Diabetes Association. The cost of diabetes. Accessed October 5, 2020. https://www.diabetes.org/ resources/statistics/cost-diabetes
3. American Diabetes Association. Pharmacologic approaches to glycemic treatment: Standards of Medical Care in Diabetes-2020. Diabetes Care. 2020;43(suppl 1):S98-110

4. Garber AJ, Handelsman Y, Grunberger G, et al. Consensus statement by the American Association of Clinical Endocrinologists and American College of Endocrinology on the comprehensive type 2 diabetes management algorithm 2020 executive summary. Endocr Pract. 2020;26(1):107-39.

5. Keshavarz K, Lotfi F, Sanati E, et al. Linagliptin versus sitagliptin in patients with type 2 diabetes mellitus: a network meta-analysis of randomized clinical trials. Daru. 2017;25(1):23.

6. Rascati KL, Worley K, Meah Y, Everhart D. Adherence, persistence, and health care costs for patients receiving dipeptidyl peptidase-4 inhibitors. J Manag Care Spec Pharm. 2017;23(3):299-306. doi: 10.18553/jmcp.2017.23.3.299

7. Dolinar R, Kohn CG, Lavernia F, Nguyen E. The non-medical switching of prescription medications. Postgrad Med. 2019;131(5):335-41.
8. Weeda ER, Nguyen E, Martin S, et al. The impact of non-medical switching among ambulatory patients: an updated systematic literature review. J Mark Access Health Policy. 2019;7(1):1678563.

9. Huang X, Liu Z, Shankar RR, Rajpathak S. Description of anti-diabetic drug utilization pre- and post-formulary restriction of sitagliptin: findings from a national health plan. Curr Med Res Opin. 2015;31(8):1495-500.

10. Tang Y, Huang X, Liu J, Shankar RR, Ganz ML, Rajpathak S. The effects of a sitagliptin formulary restriction program on diabetes medication use. Am Health Drug Benefits. 2017;10(9):456-62.

11. Salam T, Duhig A, Patel AA, et al. Physicians' perspectives regarding non-medical switching of prescription medications: results of an internet e-survey. PLoS One. 2020;15(1):e0225867.

12. Salam T, Duhig A, Patel AA, et al. Communication of medication nonmedical switching policies and procedures by insurance companies: results of an e-survey. Clin Ther. 2020;42(6):1077-86. 